\title{
Sustainable Packaging of Quantum Chemistry Software with the Nix Package Manager
}

\author{
Markus Kowalewski ${ }^{1}$ and Phillip Seeber ${ }^{2}$ \\ ${ }^{1}$ Stockholm University \\ ${ }^{2}$ Friedrich-Schiller-Universität Jena
}

October 19, 2021

\begin{abstract}
The installation of quantum chemistry software packages is commonly done manually and can be a time-consuming and complicated process. An update of the underlying Linux system requires a reinstallation in many cases and can quietly break software installed on the system. In this paper, we present an approach that allows for an easy installation of quantum chemistry software packages, which is also independent of operating system updates. The use of the Nix package manager allows building software in a reproducible manner, which allows for a reconstruction of the software for later reproduction of scientific results. The build recipes that are provided can be readily used by anyone to avoid complex installation procedures.
\end{abstract}

\section{Hosted file}

InlinePython.py available at https://authorea.com/users/441786/articles/542230-sustainablepackaging-of-quantum-chemistry-software-with-the-nix-package-manager

\section{Hosted file}

InteractivePythonMEEP.sh available at https://authorea.com/users/441786/articles/542230sustainable-packaging-of-quantum-chemistry-software-with-the-nix-package-manager

\section{Hosted file}

InteractiveTurbomole.sh available at https://authorea.com/users/441786/articles/542230sustainable-packaging-of-quantum-chemistry-software-with-the-nix-package-manager

\section{Hosted file}

JupyterShell.nix available at https://authorea.com/users/441786/articles/542230-sustainablepackaging-of-quantum-chemistry-software-with-the-nix-package-manager

\section{Hosted file}

MolecularModellingPin.nix available at https://authorea.com/users/441786/articles/542230sustainable-packaging-of-quantum-chemistry-software-with-the-nix-package-manager

\section{Hosted file}

MultiUserInstall.sh available at https://authorea.com/users/441786/articles/542230sustainable-packaging-of-quantum-chemistry-software-with-the-nix-package-manager

\section{Hosted file}


NonInteractiveMolcas.sh available at https://authorea.com/users/441786/articles/542230sustainable-packaging-of-quantum-chemistry-software-with-the-nix-package-manager

\section{Hosted file}

NWChemSlurm.sh available at https://authorea.com/users/441786/articles/542230-sustainablepackaging-of-quantum-chemistry-software-with-the-nix-package-manager

\section{Hosted file}

main.pdf available at https://authorea.com/users/441786/articles/542230-sustainablepackaging-of-quantum-chemistry-software-with-the-nix-package-manager 